\title{
Extrapulmonary tuberculosis: a potential source of laboratory-acquired infection
}

\author{
BW ALLEN AND JH DARRELL \\ From the Department of Bacteriology, Royal Postgraduate Medical School, London W12 0HS, UK
}

SUMMARY A three-year retrospective study has demonstrated the effect of extrapulmonary tuberculosis on safety within a routine bacteriology laboratory. The investigation showed that, from $112 \omega$ patients, 162 specimens considered to present a risk to laboratory staff were processed outside of the B1 protective area. However, it was estimated that only 51 of these specimens were heavily positive. $\overrightarrow{0}$ Of these, $57 \%$ were sputum, $30 \%$ pus, and $10 \%$ urine. Specimens of pus and urine account for $50 \%$

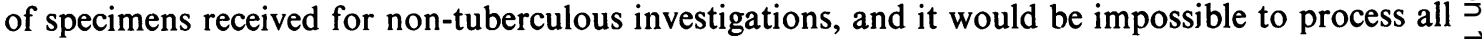
specimens that might present a risk in B1 accommodation and still maintain a high degree of safety. $\vec{\nabla}$ It is recommended that request forms which accompany specimens should clearly indicate potential $\stackrel{0}{=}$. high-risk specimens.

Surveys in Britain have shown that the risk of medical laboratory staff acquiring tuberculosis was three to five times greater than that of control groups of similar age and social status. ${ }^{12}$ These reports and other events were the prelude to codes of practice. The first, prepared by the Public Health Laboratory Service, dealt with safety in working with tuberculous material. ${ }^{3}$ The Howie code of practice for the prevention of infection in clinical laboratories was later published by the Department of Health and Social Security. 4 It has been recommended that priority be given to the implementation of those measures directly relating to tuberculosis and hepatitis. ${ }^{5}$ The Howie code's most important recommendation is for the use of special accommodation when working with category B1 organisms, which includes the pathogenic mycobacteria. Within this accommodation all clinical material and cultures should be handled in category 1 microbiological safety cabinets designed to British Standard specification. ${ }^{6}$

Sputum is generally regarded as the clinical specimen most likely to contain tubercle bacilli and therefore to present the greatest hazard to laboratory staff. ${ }^{7}$ However, the clinical presentation of tuberculosis in this country has changed considerably in recent years. Extrapulmonary tuberculosis accounts

Accepted for publication 24 September 1980 for approximately one-third of the national notifications and is even more common, amounting to over half of notifications in immigrants whose country of origin is in the Indian subcontinent. ${ }^{8}$ The British Thoracic and Tuberculosis Association survey $\overrightarrow{\overrightarrow{0}}$ of 1971 showed that more than $70 \%$ of new patients in Brent and Ealing were born outside the British Isles. ${ }^{9}$ The Hammersmith Hospital is situated in an area close to both of these boroughs and is therefore $\frac{}{0}$ well placed for investigating the effect that extrapulmonary tuberculosis may have on laboratory 3 safety.

A three-year retrospective study has been made covering the period January 1976 to December 1978. The main aim of this study was to analyse all clinical specimens that were culture positive for myco- $\frac{D}{0}$ bacteria and to assess the frequency with which these or a similar specimen from the same patient were $N$ processed in the routine laboratory outside the $N$ category B1 accommodation.

\section{Methods}

\section{CUlture POSitive Patients}

During the period investigated, a total of 129 patients were found to have had one or more specimens culture positive for mycobacteria. Of these patients, $\frac{\mathbb{D}}{\mathrm{D}}$ 78 were admitted to the Hammersmith Hospital, $48 \underset{\mathbb{\triangle}}{\stackrel{8}{8}}$ were attending the hospital as outpatients, and three 0 were admitted to the Acton Hospital. 


\section{LABORATORY ORGANISATION}

All laboratory work was carried out in the bacteriology department of the Royal Postgraduate Medical School. On arrival in the laboratory specimens accompanied by a request for examination for tuberculosis were transferred to a section dealing specifically with mycobacteria. In this section of the laboratory all techniques were performed in category 1 microbiological safety cabinets and in an area that conforms with the Howie recommendations for B1 accommodation. Specimens for investigations other than tuberculosis were examined in the routine laboratory on the open bench with the exception of sputum specimens which were processed in a category 1 cabinet housed within the routine laboratory.

\section{BACTERIOLOGICAL RECORDS}

A computer-assisted reporting and information system was in use during the entire period of the study. ${ }^{10}$ The system provides cumulative reports of bacteriological investigations, including those for tuberculosis. Using this system it was possible to recall the bacteriological records of all patients from whom at least one clinical specimen had yielded a culture positive for mycobacteria.

\section{DEFINITION OF SPECIMENS}

Specimens found to be culture positive for $M y c o-$ bacterium tuberculosis were classified as "parent

Table 1 Mycobacteria

\begin{tabular}{llcr}
\hline Organism & Type or specimen & $\begin{array}{l}\text { No. of } \\
\text { patients }\end{array}$ & $\begin{array}{c}\text { No. of } \\
\text { isolates }\end{array}$ \\
\hline M. tuberculosis & All specimens & 112 & 408 \\
M. kansasii & Sputum & 2 & 21 \\
M. xenopi & Sputum & 7 & 43 \\
$M$. bovis var BCG & Pus & 4 & 6 \\
M. fortuitum & Sputum & 1 & 2 \\
$M$. flavescens & Urine & 1 & 1 \\
M. flavescens & Endometrial biopsy & 1 & 1 \\
$M$. gordonae & Urine & 1 & 1 \\
& Total & 129 & 483 \\
\hline
\end{tabular}

specimens'. The term 'risk specimen' was used for those which came from the same patient and clinical site as a parent specimen, were received within 10 days of the parent specimen, and were processed in the routine laboratory (outside the B1 accommodation).

\section{Results}

\section{MY COBACTER I A}

A total of 483 culture positive specimens were received from 129 patients (Table 1). Of these, 408 cultures were identified as $M$. tuberculosis. They came from 112 patients, of whom $48(43 \%)$ had pulmonary tuberculosis, $58(52 \%)$ had extrapulmonary disease, and six $(5 \%)$ presented with simultaneous pulmonary and extrapulmonary infection. Mycobacterium kansasii was repeatedly isolated from two patients and Mycobacterium xenopi from seven patients. Four patients with abscess formation after BCG vaccination yielded cultures with characteristics of BCG. The specimens from the remaining four patients yielded occasional isolates of mycobacterial species which occur more commonly as saprophytes than as pathogens. The 75 cultures other than $M$. tuberculosis were not considered to present an infection hazard, and parent specimens yielding these organisms, and their corresponding risk specimens, have therefore been omitted from the remainder of the results.

\section{SPECIMEN TYPE AND DEGREE OF POSITIVITY}

Table 2 sets out the type of parent and risk specimens received, and the number of heavily positive parent specimens, defined as those yielding more than 100 colonies on a slope of culture medium. The number of heavily positive risk specimens was estimated on the assumption that these specimens would occur in the same proportion of risk specimens as had occurred in the parent specimens. Sputum accounted for $67 \%$ of 408 parent specimens, pus for a further $13 \%$, and urine for $8 \%$. Among the 162 risk specimens, only

Table 2 Origin and degree of positivity of parent specimens and origin and estimated positivity of risk specimens

\begin{tabular}{|c|c|c|c|c|c|c|c|c|}
\hline \multirow[t]{3}{*}{ Type of specimen } & \multicolumn{4}{|c|}{ Parent specimens } & \multicolumn{4}{|c|}{ Risk specimens } \\
\hline & \multicolumn{2}{|l|}{ All } & \multicolumn{2}{|c|}{$\begin{array}{l}\text { Yielding }>100 \\
\text { colonies }\end{array}$} & \multicolumn{2}{|l|}{$A l l$} & \multicolumn{2}{|c|}{$\begin{array}{l}\text { Estimated }>100 \\
\text { colonies }\end{array}$} \\
\hline & No. & $\%$ & No. & $\%$ & No. & $\%$ & No. & $\%$ \\
\hline $\begin{array}{l}\text { Sputum and gastric lavage } \\
\text { Pus } \\
\text { Urine } \\
\text { Lymph glands } \\
\text { Fluids } \\
\text { Tissue } \\
\text { C.S.F. }\end{array}$ & $\begin{array}{r}276 \\
55 \\
31 \\
15 \\
15 \\
14 \\
2\end{array}$ & $\begin{array}{c}67 \\
13 \\
8 \\
4 \\
4 \\
3 \cdot 5 \\
0 \cdot 5\end{array}$ & $\begin{array}{r}150 \\
17 \\
6 \\
3 \\
0 \\
1 \\
0\end{array}$ & $\begin{array}{l}85 \\
10 \\
3 \\
1 \cdot 5 \\
0 \\
0 \cdot 5 \\
0\end{array}$ & $\begin{array}{r}54 \\
50 \\
27 \\
6 \\
17 \\
5 \\
3\end{array}$ & $\begin{array}{r}33 \\
31 \\
17 \\
4 \\
10 \\
3 \\
2\end{array}$ & $\begin{array}{l}29 \cdot 3 \\
15 \cdot 4 \\
5 \cdot 2 \\
1 \cdot 2 \\
0 \\
0 \cdot 4 \\
0\end{array}$ & $\begin{array}{r}57 \\
30 \\
10 \\
2 \\
0 \\
1 \\
0\end{array}$ \\
\hline Total & 408 & 100 & 177 & 100 & 162 & 100 & $51 \cdot 5$ & 100 \\
\hline
\end{tabular}


$33 \%$ were sputum while pus $(31 \%)$, urine $(17 \%)$, and other fluids $(10 \%)$ were more often encountered. Of the 177 heavily positive parent strains, $85 \%$ were from sputum and $10 \%$ from pus, other specimen types rarely yielding more than 100 colonies. In contrast, only $57 \%$ of the estimated heavily positive risk specimens were sputum, while $30 \%$ were pus, and $10 \%$ urine.

SEQUENCE OF PARENT AND RISK SPECIMENS Analysis of the dates of receipt of parent and risk specimens in the laboratory (Table 3) shows that the great majority of risk specimens were received before the parent strain could have been recognised as being positive for acid-fast bacilli by microscopy. Of the 162 risk specimens, $87 \%$ arrived before or on the same day as the parent specimen and a further $10 \%$ during the next five days. In the 20 instances in which specimens were received during the 10-day period after the parent specimens, 16 of the parent specimens were smear negative. Thus only four of the 162 risk specimens could have been recognised as a potential infection risk by examination of the parent specimen.

NOTIFICATION OF RISK ON REQUEST FORM Of the request forms received with the 108 nonsputum risk specimens, $94 \%$ were still available, but only $37 \%$ were available from those received with the 54 specimens of sputum. A clinical diagnosis of possible tuberculosis was made on only $24 \%$ of the request forms for the 101 non-sputum specimens.

\section{Discussion}

At first sight it was surprising to find that $57 \%$ of culture-positive patients in this study had extrapulmonary tuberculosis, but this finding was no doubt due to the large immigrant population served. Sputum was, however, the most frequent culturepositive specimen, multiple specimens being sent from each patient because of the ease with which it is obtained. As specimens other than sputum were found to be less heavily positive, it may be argued, they present less risk. It is also probable that some

Table 3 Interval between receipt of parent and risk specimens

\begin{tabular}{lccrr}
\hline Receipt of risk specimen & Sputum & Non-sputum & Total & $\%$ \\
\hline 6-10 days before parent & 2 & 4 & 6 & 4 \\
1-5 days before parent & 14 & 32 & 46 & 28 \\
Same day as parent & 34 & 56 & 90 & 55 \\
1-5 days after parent & 3 & 13 & 16 & 10 \\
6-10 days after parent & 1 & 3 & 4 & 3 \\
Total & 54 & 108 & 162 & 100 \\
\hline
\end{tabular}

specimens, because of their viscosity, for example, tissue and pus, are less likely to create an infective aerosol than specimens such as urine. However, the hazards produced in laboratories by infective droplet-nuclei are a direct result of the techniques used during the examination of specimens. For instance, homogenisation, centrifugation, and preparation of smears are all techniques known to produce aerosols. ${ }^{11}$

If one considers the nature of the risk specimens, those specimens yielding more than 100 colonies are most likely to be an infection risk. Of these, $57 \%$ were sputum but $30 \%$ were pus and $10 \%$ urine. The Howie code recognises sputum as the most hazardous clinical specimen. However, it does not take account of other specimens. In our laboratory, specimens of pus and urine account for $50 \%$ of the bacteriological specimens received for routine (non-tuberculous) investigation. If we were to avoid exposure to all of the specimens that contain numerous tubercle bacilli, $50 \%$ (approximately 30000 ) of the specimens would be processed in category 1 cabinets. It would be impossible to process all of these specimens in B1 accommodation and at the same time preserve the concept that this accommodation is a separate and special area designed specifically for high-risk work. Rather than process all specimens that might contain B1 pathogens in special accommodation it would be more efficient to be able to identify the small proportion of specimens, sent for routine examination, that are likely to contain these pathogens. This might be achieved if request forms were labelled in a manner easily recognisable by laboratory staff to indicate the infection risk. In this study, however, it was rare for request forms from these specimens to have any indication that they might present an infection risk and even rarer for the message to be comprehensible to clerical and technical staff.

We are grateful to Professor DA Mitchison for his valuable advice during this investigation, and to Mrs $\mathrm{J}$ Perry for the computer analysis program which formed the basis of this work.

\section{References}

1 Reid DD. Incidence of tuberculosis among workers in medical laboratories. $\mathrm{Br} \mathrm{Med} J$ 1957;ii:10-4.

${ }^{2}$ Harrington JM, Shannon HS. Incidence of tuberculosis, hepatitis, brucellosis, and shigellosis in British medical laboratory workers. $\mathrm{Br} \mathrm{Med} J$ 1976;i :759-62.

${ }^{3}$ Precautions against tuberculous infection in the diagnostic laboratory. Mon Bull Ministry of Health \& PHLS 1958; 17:10-8.

4 Department of Health and Social Security. Code of practice for the prevention of infection in clinical laboratories and post-mortem rooms. London: HMSO, 1978. 
${ }^{5}$ Department of Health and Social Security health circular. $1979 ; \mathrm{HC}(79) 3$.

- Specification for microbiological safety cabinets. British standard 5726:1979; London: British Standards Institution.

' Collins $\mathrm{CH}$. The hazards of handling sputum. The Gazette, Institute Med Lab Sci 1975;19:143.

${ }^{8}$ British Medical Research Council Tuberculosis and Chest Diseases Unit. National survey of tuberculosis notifications in England and Wales (1978-1979). In preparation.

- British Thoracic and Tuberculosis Association. A tuberculosis survey in England and Wales 1971: The influence of immigration and country of birth upon notifications.
Tubercle $1973 ; 54: 249-60$.

${ }^{10}$ Mitchison DA, Darrell JH, Mitchison R. A computerassisted bacteriology reporting and information system. J Clin Pathol 1978;31 :673-80.

11 Collins CH, Hartley EG, Pilsworth R. The prevention of laboratory acquired infection. Pub Hlth Lab Serv Monograph 1974;6: London: HMSO.

Requests for reprints to: Mr BW Allen, Bacteriology Department, Royal Postgraduate Medical School, Hammersmith Hospital, London W12 0HS. 